\title{
Hysteroscopic salpingosonography: a novel technique for infertile patients
}

\author{
Garima Kapoor $^{1}$, Bindu Bajaj ${ }^{1 *}$, Usha Rani ${ }^{1}$, Geeta Pardeshi ${ }^{2}$
}

\begin{abstract}
${ }^{1}$ Department of Obstetrics and Gynecology, ${ }^{2}$ Department of Community Medicine, VMMC and Safdarjung Hospital,
\end{abstract} New Delhi, India

Received: 11 June 2019

Accepted: 09 July 2019

\section{*Correspondence:}

Dr. Bindu Bajaj,

E-mail: bindu_bajaj@yahoo.com

Copyright: () the author(s), publisher and licensee Medip Academy. This is an open-access article distributed under the terms of the Creative Commons Attribution Non-Commercial License, which permits unrestricted non-commercial use, distribution, and reproduction in any medium, provided the original work is properly cited.

\section{ABSTRACT}

Background: Infertility is akin to curse in our country. Patients of infertility run from pillar to post to get relief. Government Hospitals in India lie at the tail end of window-shopping of infertility centres by the patients having exhausted all their resources. Patients report without any detailed records, lost reports, coming after long hiatus of having stopped treatment in desperation, making one wonder how to proceed. At the other end are patients who have undergone laparotomy for various reasons like intestinal obstruction, tubercular abdomen, adnexal masses and their tubal status is not very clear on HSG. So, repeat laparoscopy in the former group and performing ab initio in the latter, involves putting the patients to the risk of general anesthesia, injury to internal organs due to anticipated adhesions. Although Hassan's technique of open trocar entry is well accepted the first port entry, whatever be the mode, is an entry open to risks.

Methods: In a selected group of infertile women, a baseline TVS was done on 2/3 day of menses and on the 7/8 day of menstrual cycle hysteroscopy was done which was immediately followed by another transvaginal ultrasound. The descriptive statistics is presented in the form of percentages and appropriate graphs.

Results: Among the 54 patients who underwent this procedure, $65 \%$ had normal uterine cavity. $18 \%$ were referred for IVF. $9.2 \%$ conceived post procedure.

Conclusions: Successive use of transvaginal ultrasound after hysteroscopy i.e Hysteroscopic sonosalpingography is a useful procedure in a select group of infertile patients.

Keywords: Controlled ovarian stimulation, Hysteroscopy, Intrauterine insemination, Timed intercourse, Transvaginal ultrasound

\section{INTRODUCTION}

Infertility is a bane of the rich and the poor alike. These patients not only have a myriad of organic pathologies but also carry a large baggage of emotional issues. To be able to help them is very gratifying. Tubal pathology is the reason behind the invent of IVF technique. But in our country, IVF is still a distant dream for many and we see in Government Hospitals patients coming year after year in the hope of getting pregnant naturally. This includes patients reporting without any detailed records, lost reports, coming after long hiatus of having stopped treatment in desperation, making one to wonder how to proceed. At the other side of spectrum are patients who have undergone laparotomy for various reasons like intestinal obstruction, tubercular abdomen, adnexal masses and their tubal status is not very clear on HSG. So, repeat laparoscopy in the former group and 
performing for the first time in the latter involves putting the patients to the risk of general anesthesia, and injury to internal organs due to anticipated adhesions. For this subgroup of patients, it was decided to explore the option of transvaginal ultrasound, immediately following hysteroscopy. The objective was that if either of the tubes were patent, the fluid through the uterus during hysteroscopy would flow through them and accumulate in the pouch of Douglas, which could be detected on TVS ultrasound. Once assured regarding the patency of tubes, we may proceed to COI and IUI and give patient some chance to conceive till she is ready financially and emotionally to avail of an IVF procedure. Hysteroscopy is the gold standard procedure for uterine cavity exploration. ${ }^{1}$

This study recommends the novel concept of using hysteroscopy along with ultrasound for not only diagnosing and treating endometrial pathologies, but also identifying tubal patency in a select group of patients as an alternative to repeat laparoscopies/laparotomies.

\section{METHODS}

A total of 900 patients reporting to infertility clinic in Safdurjung hospital during the time period July 2017May 2018 were screened for suitability to be included in this study. The patients fulfilling the inclusion criteria underwent hysteroscopy followed by TVS. Office hysteroscope is a small $4 \mathrm{~mm}$ device, which is easy to use and does not need any cervical dilatation. ${ }^{1}$ The abnormal findings found on hysteroscopy were polyp, septa, adhesions, chronic inflammation. ${ }^{2}$

\section{Inclusion criteria}

- The Women with history of abdominal surgery with one or both tubes blocked / partially blocked on HSG

- Laparoscopy already done on patient where tubal status not is in determinate with the report provided/ report not available

- Failure to conceive following previous $\mathrm{COH}$ and TI /IUI and not wishing to undergo laparoscopy.

\section{Exclusion criteria}

- Presence of any active infection-Pelvic inflammatory disease, Tuberculosis.

A total of 54 patients fulfilled the inclusion criteria. Informed consent was taken from these patients. Institutional ethical committee's approval was also obtained. A baseline TVS was done on day $2 / 3$ of menses. Hysteroscopy was performed on day $7 / 8$ of the menstrual cycle under intravenous sedation (pentazocine $30 \mathrm{mg}$, promethazine $25 \mathrm{mg}$ ). A bottle of $500 \mathrm{ml}$ or less normal saline was sufficient to perform the procedure. All patients tolerated the procedure well. A note was made of endocervical canal, endometrial cavity (any pathology like uterine synechiae, fibroids etc.) and status of bilateral Ostia (visibility, distensibility, currents). A see and treat policy was adopted for patients with many pathologies like uterine synechiae, small endometrial polyps). After hysteroscopy, patients underwent trans vaginal ultrasound (TVS) using a 7.5 $\mathrm{MHz}$ transducer. A note of the follicle count per ovary, endometrium, free fluid in pouch of Douglas, any adnexal pathology particularly a hydrosalpinx, adhesions in pod was made.

\section{Statistical analysis}

The descriptive Statistics was presented in the form of percentages and appropriate graphs.

\section{RESULTS}

A total of 54 patients fulfilling the inclusion criteria were included in the study. $59.2 \%$ had primary infertility and out of these $78.1 \%$ were less than 30 yrs of age.

Only $500 \mathrm{ml}$ of saline was used for hysteroscopy, as this was sufficient to give full view of the uterus and observe anamolies and current of fluid in the Ostia. Anything in excess of $500 \mathrm{ml}$ of saline is unnecessary especially for patients with preexisting hydrosalpinx (where it was carefully avoided in this study).

Table 1: Age distribution of women according to type of infertility.

\begin{tabular}{|llllll|}
\hline Age & No. & Primary infertility & $\%$ & Secondary infertility & $\%$ \\
\hline $20-25$ & 9 & 7 & 77.7 & 2 & 22.2 \\
\hline $25-30$ & 29 & 18 & 62.06 & 11 & 37.9 \\
\hline $30-35$ & 13 & 5 & 38.4 & 8 & 61.5 \\
\hline $35-40$ & 3 & 2 & 66.6 & 1 & 33.3 \\
\hline Total & 54 & 32 & 59.2 & 22 & 40.8 \\
\hline
\end{tabular}

The uterine cavity was found to be normal in $64.81 \%$ patients (Table 2). Septate uterus was found in 4 patients and only one patient exhibited chronic inflammatory changes and was further investigated to rule out tuberculosis. Abnormal ostia were present in three patients. These ostia were either pinpoint or dilated looking. 
Table 2: Hysteroscopic findings.

\begin{tabular}{|lll|}
\hline Findings & No. of patients & $\%$ \\
\hline Normal cavity & 35 & $64.81 \%$ \\
\hline Abnormal ostia & 03 & $5.5 \%$ \\
\hline Adhesions in cavity & 06 & $11.11 \%$ \\
\hline Septate uterus & 04 & $7.4 \%$ \\
\hline Polyp & 05 & $9.2 \%$ \\
\hline Chronic inflammation & 01 & $1.8 \%$ \\
\hline Deep seated ostia (b/l) & 04 & $7.4 \%$ \\
\hline Calcified endometrial cavity & 01 & $1.8 \%$ \\
\hline
\end{tabular}

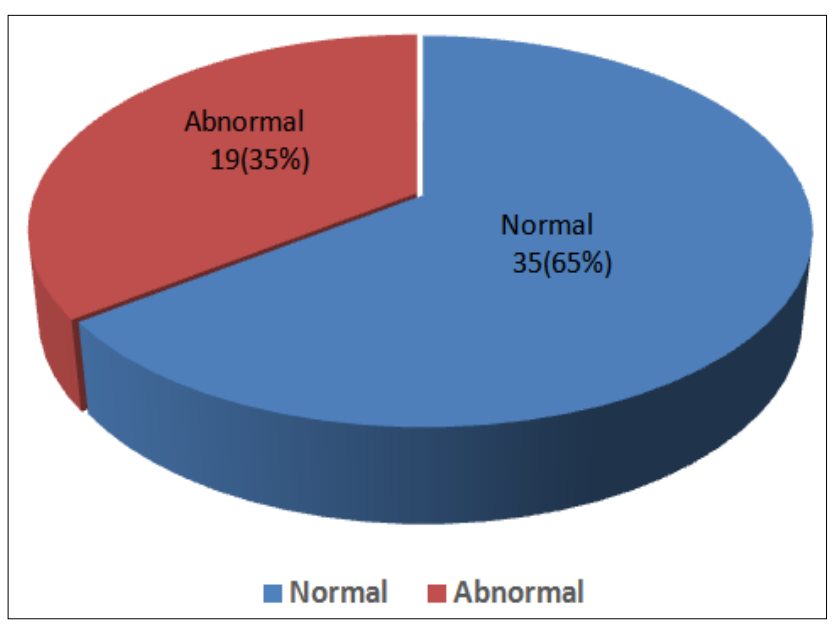

Figure 1: Pictorial representation of uterine cavity, adnexa and surroundings post hysteroscopy on TVS ultrasound.

Table 3: Post hysteroscopic TVS ultrasound findings

\begin{tabular}{|lll|}
\hline Findings & $\begin{array}{l}\text { Number } \\
\text { of patients }\end{array}$ & $\%$ \\
\hline $\begin{array}{l}\text { Normal uterus with fluid in } \\
\text { POD }\end{array}$ & 35 & 64.81 \\
\hline Nil fluid in pod & 10 & 18 \\
\hline Minimal fluid in pod & 09 & 17 \\
\hline Polyps & 05 & 9.2 \\
\hline Hydrosalpinges U/l or B/l & 02 & 3.7 \\
\hline Fluid in endometrial cavity & 01 & 1.8 \\
\hline Peritoneal adhesions & 01 & 1.8 \\
\hline
\end{tabular}

Sufficient time was given at hysteroscopy once endometrial cavity was entered to ensure fluid trickling into the abdomen through open tubes. $64.81 \%$ patients showed sufficient fluid in Pouch of douglas post hysteroscopy (Table 3).

In one patient the fluid was trapped in endometrial cavity which on follow up cleared later. There was one patient each showing unilateral and bilateral hydrosalpinges. One patient had peritoneal adhesions seen as thin septa floating in the pouch of douglas. On Post hysteroscopy ultrasound $35 \%$ patients had some abnormal finding (Figure 1).

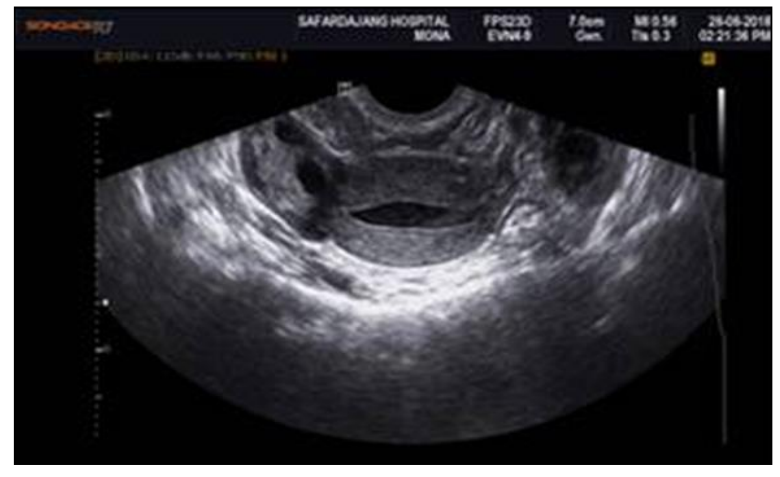

Figure 2: Ultrasound picture depicting fluid in endometrial cavity post hysteroscopy.

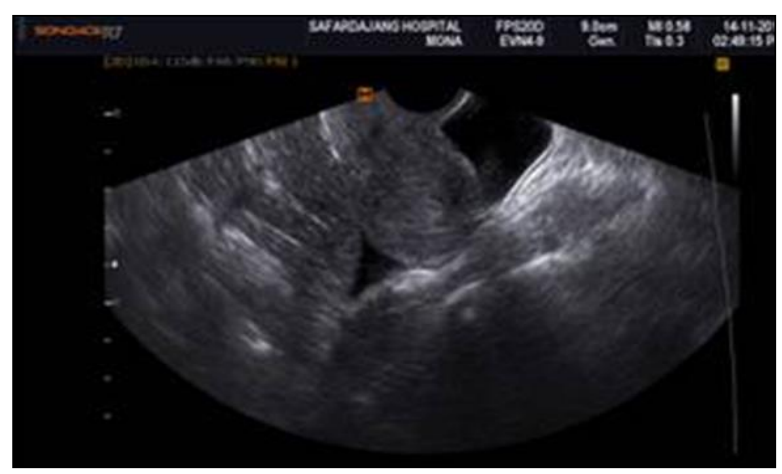

Figure 3: Ultrasound picture of fluid seen around uterus.

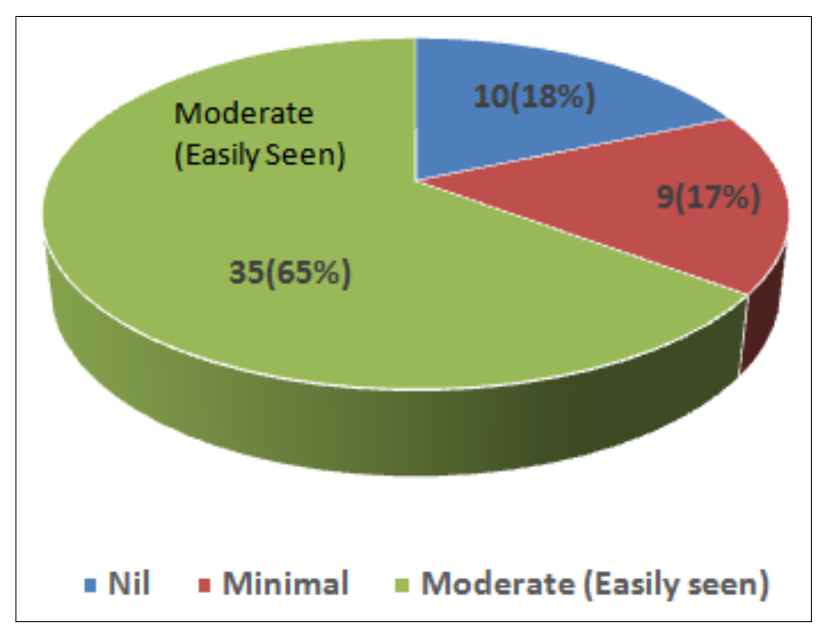

Figure 4: Pictorial representation of Fluid in POD on TVS (n=54).

In the present study there were two cases of hydrosalpinx already diagnosed on HSG. Post procedure, the size of one increased. Since patient was asymptomatic, she was kept under observation and it returned to its original size within a week. Another patient, who had calcification in the uterine cavity on ultrasound and hysteroscopy on histopathological examination, was diagnosed to be tubercular. Among the entire patients 65\% showed moderate amount of fluid in pouch of Douglas indicative of patency of at least one tube. However, 9\% showed 
minimal fluid and these patients though given OI and IUI did not conceive and $18 \%$ patients were directly referred for IVF.

\section{DISCUSSION}

In this study, $64.81 \%$ patients had normal intrauterine cavity, which is similar to the findings of Hinckley, Mary $\mathrm{D}$ et al. ${ }^{2,3}$ The authors in their study did hysteroscopy in all patients coming for IVF, while we selected a targeted group of patients, in whom adhesions were more likely.

Burney RO et al, reported $7.5 \%$ patients of infertility with intrauterine adhesions, whereas $11.1 \%$ of our patients had adhesions. ${ }^{4}$ These may be missed on routine hysterosalpingography and even by sonohysterography. The higher incidence in our study can be explained as selected patients had history of previous surgeries. The previously published data on hysteroscopy shows large variations of abnormal findings i.e. presence of polyp, adhesions, septa, bicornuate uterus, inflammation etc. between the studies ( $7.2 \%$ to $64 \%){ }^{5-10}$ These studies have performed hysteroscopies in patient going for IVF. The intrauterine defect seen by saline infusion sonohysterography were reported to be $16.2 \%$ by Turkaspa et al, where-as rates of abnormal findings in unselected infertile patient who underwent diagnostic hysteroscopy ranged from $30 \%$ at 30 years in the study by Koskas $\mathrm{M}$ et al. ${ }^{11}$ In the present study, 5 patients $(9.2 \%)$ conceived after this procedure, all of whom had undergone ovulation Induction and IUI. These were repeat stimulations after inability to conceive earlier. Saline flush following Hysteroscopy may be credited for clearing the mucus plugs in the fallopian tube in these cases or it could be due to endometrial tickle theory. ${ }^{12}$ Confirmation of tubal patency allowed us to proceed with OI and IUI. Of the five patients who got pregnant following the procedure, four had normal uterine cavity and one had adhesions. This patient had two previous caesareans with secondary infertility with no live issue and underwent adhesiolysis. She conceived with IUI and was diagnosed to have placenta percreta. She was provided with good supportive antenatal care, and was planned for elective caesarean. Bilateral internal iliac balloon placement was done under fluoroscopic guidance prior to caesarean and balloons inflated on the OT table. However, despite the balloon occlusion, the patient had severe postpartum hemorrhage and had to undergo caesarean hysterectomy. She was discharged with a healthy baby girl.

A saline ultrasound (Sonohysterography) is an already existing and well-accepted alternative. ${ }^{13-14}$ However, it needs logistics of doing it in the ultrasound room along with paraphernalia of introducing Foleys catheter in the uterus and need for IV set etc. Whereas in the OT, minor therapeutic procedures like adhesiolysis, polypectomy of the polyps in the cervix/uterine cavity can be done in the same sitting. A baseline TVS was done on day $2 / 3$ of menses.
Drawback of our procedure unlike laparoscopy is that abdominally tubo-ovarian relationship cannot be improved, endometriosis, particularly mild, may be missed, intra-abdominal adhesiolysis and ovarian drilling in PCOS patients is not possible. This procedure is not a substitute for laparoscopy but a useful simple alternative in a selected subgroup only.

This provides an indication of tubal patency but may not point to the side of patency. This further makes ovulation induction cycles frivolous sometimes when same side tube may be blocked. In spite of these drawbacks it is still a useful procedure.

\section{CONCLUSION}

The simplification of the hysteroscopic techniques widens our spectrum for the ambulatory screening of the uterus. Both Hysteroscopy and Ultrasound have been used as a first-line diagnostic tool to evaluate the uterine cavity in the infertile patient. There is high patient compliance and low complication rate when both are combined.

\section{Recommendations}

Authors recommended (Hysterosalpingosonography) hysteroscopy followed by ultrasonography i.e. their consecutive use as an indicator of tubal patency, to identify and treat much endometrial pathology, which may be missed by ultrasound alone and other investigations. Some patients may benefit from a see and treat policy, thus saving their time, resources and preventing them complications of anaesthesia. This study recommends this procedure in a select group of patient though it cannot substitute for laparoscopy. Another study where ultrasound is done simultaneously with hysteroscopy will be in order.

\section{ACKNOWLEDGMENTS}

Authors would like to thank the patients.

Funding: No funding sources

Conflict of interest: None declared

Ethical approval: The study was approved by the Institutional Ethics Committee

\section{REFERENCES}

1. Koskas M, Mergui JL, Yazbeck C, Uzan S, Nizard J. Office hysteroscopy for Infertility: a series of 557 consecutive cases. Obstet Gynecol Int. 2010:168096.

2. Mary D Hinckley, Amin A. Milki. 1,000 Office hysteroscopies for infertility: feasibility and findings September. 2003:80(3):82-3.

3. Campo R, Van Belle Y, Rombauts L, Brosens I, Gordts S. Office mini hysteroscopy. Hum Reprod Update. 1999;5(1):73-81. 
4. Burney RO, Moayeri SE, Milki AA, Westphal LM, Lathi RB. Fertility and sterility. Sept. 2005;84(1):S469.

5. Dicker D, Goldman JA, Ashkenazi J, Feldberg D, Dekel A. The value of hysteroscopy in elderly women prior to in vitro fertilization embryo transfer (IVF-ET). 1990;7(5):267-70.

6. Brusco GF, Arena S, Angelini A. The role of diagnostic hysteroscopy in infertile women. Minerva Ginecol. 2001;53(5):313-9.

7. Preuttipan S, Linasmita V. A prospective comparative study between hysterosalpingography and hysteroscopy in the detection of intrauterine pathology in patients with Infertility. $\mathbf{J}$ Obst Gynaecol Res. 2003;29(1):33-7.

8. Pansky M, Feingold M, Sagi R, Herman A, Schneider D, Halperin R. Diagnostic Hysteroscopy as a primary tool in a basic infertility workshop. JSLS. 2006;10(2):231-5.

9. Campo R, Meier R, Dhont N, Mestdagh G, Ombelet W. Implementation of hysteroscopy in an infertility clinic: The one stop uterine diagnosis and treatment. Facts Views Vis Obgyn. 2014;6(4):235-9.

10. Brown SE, Coddington CC, Schnorr J, Toner JP, Gibbons W, Oehninger S. Evaluation of outpatient hysteroscopy, saline infusion hysterosonography, and hysterosalpingography in infertile women: a prospective randomised study. Fertil steril. 2000;74(5):1029-34.

11. Tu-kaspa I, Gal M, Hartman J, Hartman A. A prospective evaluation of uterine abnormalities by saline infusion sonohysterography in 1,009 women with infertility or abnormal uterine bleeding. Fertil Steril. 2006;86(6):1731-5.

12. Wang SL, Burney RO, Moayeri SE, Milki AA, Lathi RB. Effect of diagnostic hysteroscopy with or without mechanical disruption of the endometrium in the infertile population. 2008;90:S39-406.

13. Diaferia D, Ragni G, Vegetti W, Colombo M, Arnoldi M, Crosignani PG. Sonohysterography for uterine cavity evaluation in infertility work up. Sept. 2000;74(3):S30.

14. Santhana L, Kumara S, Parvatha V. Evaluation of tubal patency by sonosalpingography in infertile women. Int J Repro Contrac Obstet Gynecol. Available at: http://dx.doi.org/10.18203/23201770.ijrcog20175038.

Cite this article as: Kapoor G, Bajaj B, Rani U, Pardeshi G. Hysteroscopic salpingosonography: a novel technique for infertile patients. Int J Reprod Contracept Obstet Gynecol 2019;8:3271-5. 